\title{
Grupo de convivência em saúde mental: intersetorialidade e trabalho em rede
}

\author{
Luís Felipe Ferro
}

Universidade Federal do Paraná, Curitiba, PR, Brasil.

\begin{abstract}
Resumo: Introdução: Os últimos 20 anos têm sido profícuos na regulamentação legislativa do processo da Reforma Psiquiátrica, proporcionando a edificação de equipamentos voltados a aliar acompanhamento clínico comunitário a propostas de inclusão social de sua população alvo. Para tanto, a prerrogativa do trabalho em rede torna-se imprescindível. Nesse panorama, o Departamento de Terapia Ocupacional da Universidade Federal do Paraná, em parceria com uma associação de Curitiba, vem desenvolvendo um Grupo de Convivência enquanto dispositivo de atendimento para pessoas com transtorno mental. Objetivos: É intenção do artigo analisar alguns dos desafios para a prática do trabalho em rede, tendo como fundo argumentativo a experiência de condução do grupo e relatos de seus participantes. Métodos: Para alcançar os objetivos propostos, apresenta-se aqui o resultado da congregação de duas aproximações metodológicas: relato de experiência de três anos de condução do grupo e pesquisa qualitativa de caráter exploratório. Utilizaram-se, como técnica de coleta de dados, entrevistas não estruturadas focalizadas com 11 usuários do grupo e a análise dos dados foi efetuada por meio da análise hermenêutico-dialética. Resultados e conclusão: Pôde-se observar a necessidade de trabalho conciso e contínuo junto aos usuários, tecido em parceria com serviços envolvidos em seu encaminhamento e acompanhamento. A garantia dos direitos sociais básicos mostra-se imprescindível para a efetividade da inclusão social desses indivíduos.
\end{abstract}

Palavras-chave: Saúde Mental, Terapia Ocupacional, Prática de Grupo, Assistência à Saúde, Ação Intersetorial, Integralidade em Saúde.

\section{Group living in mental health: intersectorality and networking ${ }^{1}$}

\begin{abstract}
Introduction: The last 20 years has been fruitful to the Psychiatric Reform legislative regulation, creating equipments focused on ally communitarian clinical followup to social inclusion proposals of their target population, therefore the prerogative of network becomes imperative. The Occupational Therapy Course of Federal University of Parana in partnership with an Association in Curitiba has developed Group living as a therapeutic tool for people with mental disorders. Objective: In order to analyze some of the barriers for network's practice, having as an argumentative background 3 years of experience in conducting the group and the reports of its users. Methods: To achieve the proposed objectives, the results of two methodological approaches are here presented: the experience report in conducting the group and a qualitative-exploratory field research. Data collection was performed using unstructured focused interviews with 11 group participants and the data analysis was carried out through hermeneutic-dialectic analysis. Results and conclusion: We observed the need for a concise and continuous work with the users, in partnership with the involved services that route and assist them. The guarantee of basic social rights appears as essential for the effectiveness of social inclusion of these people.
\end{abstract}

Keywords: Mental Health, Occupational Therapy, Group Practice, Delivery of Health Care, Intersectorial Action, Integrality in Health.

Autor para correspondência: Luís Felipe Ferro, Universidade Federal do Paraná, Avenida Prefeito Lothário Meissner, 632, Jardim Botânico, CEP 80210-170, Curitiba, PR, Brasil, e-mail: luisfelipeferro@gmail.com

Recebido em Jul. 29, 2014; $1^{\text {a }}$ Revisão em Nov. 18, 2014; Aceito em Fev. 6, 2015. 


\section{Introdução}

O movimento de Reforma Psiquiátrica no Brasil acusa de maneira severa diversos dos processos de exclusão social. Equipamentos como manicômios passaram a ser criticados em suas propostas basais e, paulatinamente, vêm sendo desmontados (ANTUNES; BARBOSA; PEREIRA, 2002; AMARANTE, 2003; BRASIL, 2004a, 2011).

O reposicionamento estratégico da política pública em saúde mental inclinou ações e serviços de modo a subsidiar práticas de acompanhamento clínico conjugadas a propostas de inclusão social de sua população-alvo (BRASIL, 2004b; FERRO, 2009). Centros de Atenção Psicossocial (CAPS), Estratégia de Saúde da Família (ESF), Núcleo de Apoio à Saúde da Família (NASF), Unidades de Acolhimento, Consultórios na Rua, Leitos e Unidades Psiquiátricas em Hospitais Gerais, e Centros de Convivência e Cultura são alguns dos equipamentos erigidos sob essa égide, que dão configuração à preconizada Rede de Atenção Psicossocial - RAPS (FONSECA, 2008; FASSHBER; VIDAL, 2007; BAZHUNI, 2011; BRASIL, 2004a, 2011; SOUZA; PEREIRA; GONTIJO, 2014).

A partir desse panorama, açóes de diferente sorte passaram a ser elaboradas para proporcionar repertório para a busca da pragmatizaçáo das diretrizes propostas pela RAPS. Terapia Comunitária, açóes de educação em saúde, Grupos de Geração de Trabalho e Renda, práticas corporais e integrativas, grupos de cidadania e controle social, Acompanhamentos Terapêuticos, Grupos de Convivência, etc. proporcionam, em atual configuração social, algumas das possibilidades de atuação de agentes da saúde para a construção e a maximização de trocas sociais, afetivas e comunitárias de sua populaçáo-alvo (CHIAVERINI, 2011; FERRO et al., 2012, 2013a; FILIZOLA et al., 2011; BRASIL, 2005; MOURA et al., 2014; SILVA; CORTEGOSO; LUSSI, 2014; KINKER, 2014).

Para edificar tal empreitada, a RAPS tem, ao menos legislativamente, a base estrutural dos Projetos Terapêuticos Singulares (PTS), para orquestrar os diferentes equipamentos e açôes (BRASIL, 2011). Ao PTS, é imprescindível a compreensão ampliada dos processos de saúde e doença, e, em sua elaboração e execução, aspectos subjetivos do usuário unem-se a problemáticas e potencialidades familiares e comunitárias para proporcionar a composiçáo de intervençóes integradas que tenham como foco a estruturação de projetos de vida. É esperado, ainda, sinergismo entre os diversos agentes e setores sociais para a construção de propostas de enfrentamento das problemáticas vivenciadas pelos usuários dos serviços de saúde mental, seus familiares e comunidade, no sentido de compor PTS individuais e coletivos (OLIVEIRA, 2007).

Essa perspectiva, logo, transborda de maneira enfática o campo da saúde, convocando diferentes profissionais e agentes sociais para a elaboração de açôes frente às dificuldades vivenciadas por usuários no percurso de sua inclusão social, seja no campo do trabalho, seja nas esferas de esporte, lazer, cultura, moradia, saúde, alimentação, educação, etc. É nesse sentido que o trabalho em rede torna-se mister enquanto direcionamento para as açôes públicas (BRASIL, 2011).

Em relação orgânica com esse quadro, o Departamento de Terapia Ocupacional da Universidade Federal do Paraná (UFPR), em parceria com a Associação Arnaldo Gilberti (AAG), investe em açôes de inclusão social dos usuários dos serviços de saúde mental da cidade de Curitiba.

A AAG é uma instituição voltada ao atendimento e à defesa dos direitos da pessoa com transtorno mental, e conta com diversos voluntários em seu cotidiano institucional. A AAG apresenta relação com a Prefeitura de Curitiba, a qual auxilia na manutenção de sua estrutura (aluguel, telefone, água e luz). Em um dos eixos de seu trabalho, configurou-se, em 2008, em parceria com o Departamento de Terapia Ocupacional, a proposta de um grupo de convivência.

Os grupos de convivência são estruturados a partir da intenção de enfrentar o isolamento social de determinados indivíduos e/ou grupos sociais, de maneira a criar "[...] espaço que favorecesse o encontro e o desenvolvimento global dos participantes" (OLIVER et al., 2004, p. 277). Reconhecidamente, é extensa a proporção de usuários dos serviços de saúde mental com considerável restrição em suas relaçóes sociais (BAZHUNI, 2011; MÂNGIA; MURAMOTO, 2007; MOURA et al., 2014), o que ressalta a importância do investimento na ampliação das redes sociais de apoio dessa população.

Sob a base estrutural do modelo da Reabilitação Psicossocial em Saúde Mental, o Grupo de Convivência foi refazendo-se de maneira inventiva, para atender a algumas das demandas apresentadas pela população atendida (FERRO et al., 2012). Metodologicamente, o Grupo acontecia semanalmente por um período de 4 a 12 horas, tendo, enquanto programação, visitaçôes a diferentes espaços sociais (parques públicos, museus, parques temáticos, etc.). Tal programação era realizada a partir do levantamento inicial das demandas dos usuários. Quanto ao fluxograma próprio ao Grupo de Convivência, usuários dos 
serviços de saúde mental eram encaminhados à AAG por profissionais de saúde mental da regiáo ou por meio da indicação de outros usuários.

Vinculada ao estágio em Terapia Ocupacional, a proposta era coordenada por um Terapeuta Ocupacional e contava semestralmente com quatro a seis estagiários, possuindo a característica de ser pouco aberto (BALLARIN, 2003). O Grupo possuía o máximo de 20 vagas, na época reservadas exclusivamente a usuários dos serviços de saúde mental da regiấo devido à grande demanda institucional advinda da AAG. Em três anos de trabalho, o Grupo acolheu cerca de 40 pessoas, contando com participação mais frequente de 12 pessoas.

Em oportunidade anterior, FERRO et al. (2012) demonstraram algumas das potencialidades e limitações do dispositivo segundo a percepção dos usuários, aprofundando reflexôes sobre a prática junto à coordenação do Grupo. Naquela oportunidade, analisamos a efetividade e as limitações do dispositivo para os seguintes aspectos: a ampliação da rede social de apoio dos participantes do Grupo; a vinculação dos usuários no território, seus equipamentos e potencialidades; a importância contributiva e as limitaçóes do Grupo enquanto dispositivo de inclusão social, e os desafios quanto à prática do Grupo para a autonomia.

Contudo, no decorrer do processo do Grupo e a partir de diferentes relatos obtidos, pudemos evidenciar alguns pontos que influenciaram de maneira substancial a coordenação do Grupo e sua efetividade, e que permeiam, acredito, de maneira sistêmica as açôes em saúde mental. Tais fatores possuem extensão mais ampla do que a localização de açóes pontuais próprias ao Grupo de Convivência (sua coordenação, agentes e instituiçóes a este vinculadas) e abrangem toda uma rede de serviços e ações públicas, direcionando as reflexôes que aqui se apresentarão no sentido da afirmação da necessidade do trabalho intersetorial e em rede, para proporcionar suporte às açóes do Grupo.

Neste momento, logo, é intenção do material que se apresenta analisar os desafios lançados para a prática do trabalho em rede de maneira aplicada a um dispositivo de atenção à saúde mental.

\section{Métodos}

O presente artigo apresenta dados obtidos por meio do projeto "Grupo de Convivência em Saúde Mental: potencialidades e limitaçôes sob a ótica de usuários", aprovado pelo Comitê de Ética em Pesquisa (CEP/UFPR) sob o n. ${ }^{\circ}$ 1074.199.10.12.
Este texto toma como base argumentativa a congregação entre o relato da experiência de três anos de coordenação do Grupo de Convivência e os relatos advindos dos usuários do Grupo, obtidos por pesquisa qualitativa. Segundo Minayo (2003), a pesquisa qualitativa busca a compreensão dos relatos/dados inserindo-os em uma determinada configuração psicossocial, marcada por processos singulares e dinâmicos. Procura aprofundar-se nos significados, motivaçóes, aspiraçóes, crenças, valores e atitudes não mensuráveis, advindos dos enunciados dos sujeitos/documentos, situando-os em determinado contexto psicossocial.

A pesquisa de campo do tipo exploratória (MARCONI; LAKATOS, 2007), realizada em 2011, junto aos usuários do Grupo de Convivência, proporcionou aos pesquisadores maior detalhamento do processo vivenciado sob a ótica dos usuários. Enquanto técnica para obtenção de dados, utilizaram-se entrevistas não estruturadas focalizadas (MARCONI; LAKATOS, 2007), compostas a partir de um roteiro-guia, procurando, contudo, garantir a possibilidade de os pesquisadores explorarem conteúdos diversos advindos dos relatos dos sujeitos. De janeiro a fevereiro de 2011, duas estudantes envolvidas na pesquisa, devidamente treinadas para a coleta de dados, entrevistaram11 participantes do Grupo de Convivência, realizado pela parceria entre o Departamento de Terapia Ocupacional da UFPR e a Associação Arnaldo Gilberti, localizada em Curitiba. A pesquisa foi, inicialmente, apresentada aos integrantes do Grupo, sendo eles, em seguida, convidados a participar da mesma. As entrevistas aconteceram em local que garantisse a privacidade dos sujeitos e foram transcritas integralmente para posterior análise.

Os usuários do Grupo, todos vinculados a serviços de saúde mental de Curitiba, foram entrevistados em momentos de estabilidade de seu quadro clínico, garantidos pelo acompanhamento sistemático realizado pelos profissionais vinculados à $A A G$. A pesquisa aconteceu com o consentimento expresso do usuário, conforme regulamenta a Lei n. ${ }^{\circ} 10.216$ (BRASIL, 2001), obtido a partir da assinatura do Termo de Consentimento Livre e Esclarecido. Para preservar o anonimato dos participantes, os sujeitos serão identificados, ao longo do corpo textual, pela letra ' $S$ ', seguida de um número.

A análise dos dados se deu por meio da matriz proporcionada pela análise hermenêutico-dialética, a qual possibilita a apreensão e a análise dos dados como resultado de um processo individual e social, permeados por fatos históricos, cotidianidade e sempre vinculados à realidade na qual ocorrem (MINAYO, 2004). Para 
a manipulaçáo pormenorizada dos dados, foram realizados os seguintes procedimentos, conforme proposto por Yin (2010): exame; categorização; tabulação (utilizamos planilha dos dados no Excel), e recombinação das informaçóes.

A partir da análise dos dados advindos das entrevistas, foram compostas três categorias, quais sejam: Rede Social de Apoio: Flutuaçóes e a continuidade do acompanhamento; Continuidade das Açôes: entre investimentos públicos e o cuidado; Grupo de Convivência: Sustentabilidade para a participação.

Previamente à apresentação das categorias, contudo, é importante maior aproximação teórica com o conceito de Redes Sociais de Apoio, o qual permitirá aprofundamento mais especializado junto ao objeto deste estudo.

\section{Redes sociais de apoio: conceitualização e subjetividade}

Com vistas a fornecer ao leitor maiores subsídios para analisar reflexivamente a prática singular de um grupo de convivência, assim como a necessidade da conjugaçáo da mesma com outros serviços e setores, é necessário de antemão explorarmos um conceito que nos é bastante profícuo: o de rede social de apoio. Para fortalecer sua apresentaçáo, optamos aqui por uma exposição às avessas, direcionando inicialmente o leitor, de maneira breve, a uma história bastante usual à saúde mental.

O Hospital Psiquiátrico, historicamente demarcado no campo da saúde como referência para o modelo de atenção em Saúde Mental adotado a partir do final do século XVIII e no século XIX, apresentava à pessoa com transtorno mental resposta social pronta às crises: a internação. $\mathrm{O}$ cidadão que viesse a sofrer de maneira severa e se enveredasse pelos caminhos da loucura, via surrupiado prontamente de sua subjetividade algo que nos é precioso: diversos de nossos papéis sociais. $\mathrm{O}$ trabalhador, o estudante, a criança, a mãe, o irmão, o atleta, o professor desapareciam frente ao fenômeno manicômio e, gradualmente, estes papéis e outros tantos cediam à marca própria da loucura.

O passeio com a família nas manhãs de sábado, a frequência assídua do trabalhador ao seu café predileto ou em necessários happy hours que seguiam intermináveis e calorosas reunióes de trabalho, paulatinamente, eram substituídos pela convivência estrita às normas muitas vezes inflexíveis do manicômio.
O manicômio desconstruía sujeitos, remodelando suas existências a moldes subjugados à sua estrutura. Vida e subjetividade, que repousavam em diferentes relaçôes e espaços de vida (café, mercado, espaços de lazer, cultura, esporte, amigos, esposa, clube - e até mesmo, em determinados momentos, hospitais), são transformadas e o pilar de suporte à subjetividade do sujeito passava a ser constituído com base exclusiva no manicômio.

O trecho acima, nada distante das vivências de diferentes pacientes e profissionais, em adição ao assombro que lhe é próprio, é, contudo, igualmente propulsor da construçáo de nova forma de estruturaçáo da atenção em saúde mental.

A subjetividade humana estrutura-se a partir da vivência em um mundo de trocas sociais. Cidadãos, na frequentaçáo de diferentes espaços em contato com outros sujeitos, experienciam momentos e encontros constituintes de uma rede que suporta $\mathrm{e}$ dá corpo à sua subjetividade. Assim, se por um lado assumimos que a diminuição vertiginosa de tal rede, proporcionada pela causa manicômio, reconfigura de maneira substancial a subjetividade dos usuários, não é verdade, por outro, que o desmonte deste espaço proporcione solução imediata ao problema. Diversos fatores - que não só o manicômio - influenciam sobremaneira a constituição de uma rede social de apoio.

O trabalho intensivo próprio ao regime capitalista, ao exemplo, pode restringir substancialmente a rede social de apoio de diferentes sujeitos. As reuniôes com amigos, a frequência ao futebol, o cuidado àquela dor lombar, tudo esvanece do cotidiano a partir de uma promoção no emprego. A rede social de apoio igualmente é desmontada. E aqui se faz imprescindível a definição de rede social de apoio.

Embora o conceito ainda esteja em composição e seja utilizado de maneira dispersa por diferentes autores $^{2}$ (VIEIRA FILHO; NÓREGA, 2004; ZACCARIN; RIVELLINI, 2000; HAYAKAWA et al., 2010; MARQUES et al., 2010; DESSEN; BRAZ, 2000), alguns trabalhos dáo enfoque principal para sua elaboração (SOUZA; SOUZA; TOCANTINS, 2009; JUSSANI et al., 2007; SILVA et al., 2014).

Uma das maneiras de compreender o conceito de rede social de apoio situa a mesma como a soma das relações que um indivíduo percebe como significativas ou diferenciadas da massa anônima da sociedade. A rede social de apoio, nesta perspectiva, é considerada como "[...] englobante de relaçôes de parentesco, amizade, relações - um círculo social constituído por traços de afinidade, formando uma teia que une as pessoas" (JUSSANI et al., 2007, p. 184-185). 
Contudo, para além da utilização do conceito na exclusividade das relaçóes de afeto e proximidade entre sujeitos, Souza, Souza e Tocantins (2009) ressaltam a necessidade de ampliaçáo para outras esferas, tornando sua aplicabilidade em saúde de grande valia. Para esses autores, a rede social de apoio pode ser de natureza primária ou secundária. As redes primárias são compostas de "[...] relaçóes de parentesco, de amizade ou de vizinhança, e estão fundadas sobre a reciprocidade e a confiança" (SOUZA; SOUZA; TOCANTINS, 2009, p. 355).

Uma contribuição importante é apresentada pelos autores Souza, Souza e Tocantins (2009) no tocante às redes sociais de apoio secundárias, classificando-as em formais e/ou informais, de terceiro setor, de mercado ou mistas. Diferenciam-se entre si pelo tipo de troca intercambiada: a reciprocidade, o direito, o dinheiro ou uma combinação desses meios.

A rede social de apoio secundária formalé composta por instituições organizacionais oficiais (unidades básicas de saúde, instituiçóes de assistência social, da educação, etc.) e "[...] se caracteriza pela prestação de serviços de acordo com as demandas das pessoas e pela troca fundada no direito" (SOUZA; SOUZA; TOCANTINS, 2009, p. 356).

Diversos indivíduos de uma comunidade com moradias em condiçóes precárias podem mobilizar-se em mutirão para se auxiliar mutuamente na construçáo de suas casas. Esta sorte de açóes configura uma rede solidária de trocas de serviços, não pautadas no dinheiro, dando contorno ao que os autores definem como rede social de apoio secundária informal.

Os autores ainda explicitam:

As redes secundárias do terceiro setor, ou organizações do terceiro setor, são associaçóes ou organizaçóes constituídas por pessoas da sociedade civil, que se situam no âmbito da prestação de serviços, mas não visam lucro; caracterizam-se pelas trocas fundadas tanto no direito como na solidariedade. Já a rede secundária de mercado diz respeito a atividades econômicas rentáveis, sendo a sua existência estreitamente ligada ao dinheiro e ao lucro como, por exemplo, empresas, estabelecimentos comerciais e clínicas de saúde privadas. Nesse caso, o intercâmbio dá-se pela troca de direito e de dinheiro (SOUZA; SOUZA; TOCANTINS, 2009, p. 356).

Em adição ao conceito elaborado pelos autores, acreditamos possível e importante a reflexão sobre o que se denominará aqui como Rede Social de Apoio Terciária.
Essa nova categoria apresenta referência às regulamentaçôes legislativas e políticas públicas próprias a determinados países e localizaçóes adstritas, que proporcionam suporte a açóes e práticas no campo tangível ao sujeito e/ou à sua comunidade. Esta categoria apresentaria, necessariamente, para compor visão crítica, análise pormenorizada e intervenções focalizadas, a subdivisão de Rede Social de Apoio Terciária Geral e Focalizada.

A Rede Social de Apoio Geral tomaria como espectro de análise diferentes políticas públicas e aparatos legislativos abrangentes a determinado País ou Estado. Políticas Públicas Nacionais ou Estaduais, benefícios e proteçôes legislativas diversas comporiam esta subcategoria e apresentariam, em nível macroestrutural, subsídios para a proteção dos sujeitos e comunidades.

Para subsidiar práticas/intervenções e responder a determinadas demandas locais, os diversos municípios comporiam aparato legislativo que lhe são próprios. Tais regulamentaçóes proporcionariam égide ao enfrentamento de problemáticas localizadas, proteçáo aos indivíduos, comunidades e grupos populacionais, constituindo o que optamos aqui por subcategorizar como Rede Social de Apoio Terciária Focalizada.

A Tabela 1 procura sistematizar de maneira a proporcionar ao leitor maior visualizaçáo do conceito agora definido de Rede Social de Apoio, ressaltando suas categorias e subcategorias.

Embora, como referido em momento anterior, a composiçáo do conceito esteja em progressão contínua, é consenso entre os diferentes autores, contudo, a relação diretamente proporcional entre rede social de apoio e a proteção, a promoção e/ou a recuperaçáo da saúde. Uma rede social de apoio fortalecida "[...] exerce influência positiva na saúde da pessoa, protegendo-a contra doenças, enquanto que, por outro lado, a pobreza relativa de relaçóes sociais constitui fator de risco para a saúde" (SOUZA; SOUZA; TOCANTINS, 2009, p. 355).

A pergunta que se faz imprescindível à saúde mental, nesse contexto é: Como fomentar e investir, em parceria com seu público-alvo, na criação e/ou no fortalecimento de sua rede social de apoio?

Distante da pretensa assunçấo da tarefa titânica de contemplar toda a complexidade da criação de uma rede social de apoio concisa através das limitaçóes óbvias de um grupo de convivência, resignar-me-ei a situar algumas das problemáticas vivenciadas cotidianamente na condução do Grupo de Convivência, afirmando no texto que se segue - o qual apresentará as categorias analíticas previamente enunciadas - a necessidade do trabalho em rede para potencializar as ações em saúde mental. 


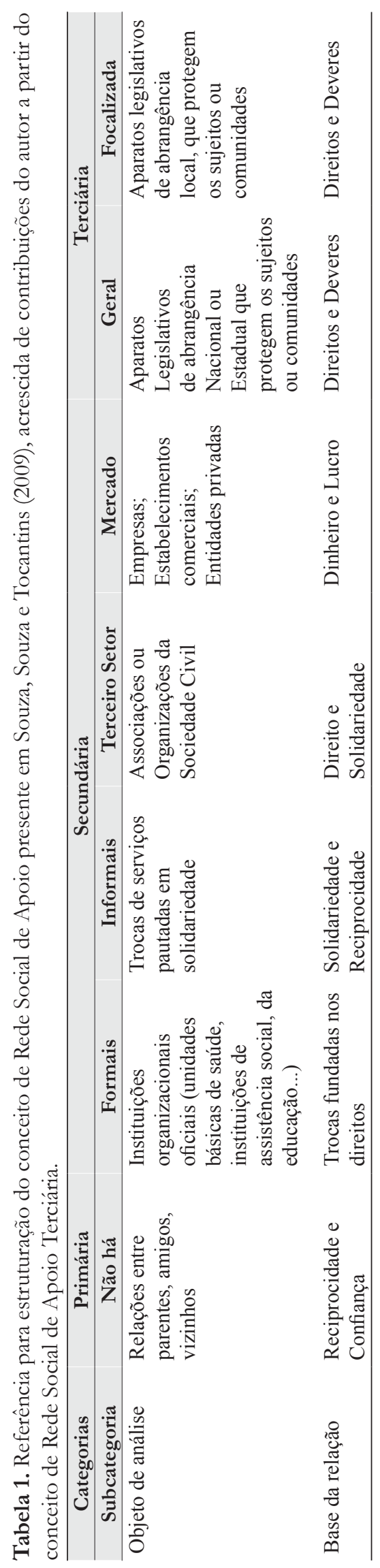




\section{Rede social de apoio:}

\section{flutuações e a continuidade do acompanhamento}

O investimento na tecitura cuidadosa da rede de atenção entre diferentes equipamentos sociais é imprescindível para possibilitar o amparo e o acompanhamento de casos diversos em saúde mental. Experiências e relatos obtidos com a experiência do Grupo de Convivência formam terreno concreto para dar suporte a esta afirmação e, com ela, reiterar a importância aplicada do conceito de redes sociais de apoio secundárias formais e de terceiro setor.

Em nossa experiência cotidiana na coordenação do Grupo de Convivência, diferentes ausências foram vivenciadas, sendo esta uma das mais importantes: a ausência de relação com outros serviços da rede.

A via única de "contato" entre equipamentos de saúde locais e o Grupo de Convivência dava-se, de maneira exclusiva, no momento de acolhimento do usuário na Associação. Alguns dos CAPS da regiâo encaminhavam o usuário para a $\mathrm{AAG}$, procurando dar estrutura à sua alta do equipamento. Os encaminhamentos, contudo, eram compostos de uma simples folha preenchida, constando, muitas vezes, a informaçáo solitária do nome e a CID do usuário. Alguns usuários, ainda, sequer conheciam as atividades oferecidas pela instituição.

Paulatinamente, fomos percebendo a dificuldade para a composição de açôes em rede pelos profissionais da saúde, com maior ênfase dada, em nosso caso, aos profissionais dos CAPS e das Unidades Básicas de Saúde (UBS) da regiấo. Como praticar um PTS conciso, se a criação de estratégias de estruturação da vida do usuário se restringe ao encaminhamento pelos profissionais da saúde a uma instituição "etérea"? Como defender a construçấo conjunta de um projeto de vida, como proposta pelo PTS, entre profissionais da saúde, usuário e familiares, se sequer as atividades da instituição são conhecidas pelo profissional encaminhador? Como defender que o incipiente "trabalho em rede" apresenta maturidade técnica quanto à elaboração concisa de um PTS? Como sustentar que o encaminhamento realizado nestes moldes não é somente uma transferência descuidada de responsabilidades? E, finalmente, a pergunta que se faz propositiva de uma nova prática: Como garantir possibilidades de corresponsabilização entre os equipamentos?

Embora o tipo acima descrito de encaminhamento demonstre esboço inicial na congregaçáo entre serviços, os encaminhamentos em papel, embora devidamente assinados e carimbados, não garantem que o usuário tenha estrutura para comparecer veementemente no local/serviço ao qual foi encaminhado. O simples encaminhamento do usuário por uma UBS ou um CAPS ao Grupo de Convivência, muitas vezes, não apresenta qualquer efetividade.

As açôes fatalmente apresentarão menor eficácia se algumas condiçóes não forem atendidas: sem o devido investimento e acompanhamento do usuário pelos profissionais das UBS ou do CAPS ao Grupo, necessário em determinados casos para garantir a real vinculação do usuário ao dispositivo e a transferência de vínculo; sem o acionamento sistemático dos profissionais do equipamento para o qual o usuário será encaminhado, apresentando informações relevantes sobre o caso e propondo pragmática parceria; sem a discussão de açôes e estratégias entre os equipamentos para determinados casos, e sem a certeza de que o parceiro, ao ser acionado, despenderá ações diversas e estrategicamente formuladas em equipe para garantir o cuidado em saúde.

Em movimento de contrapartida, o estágio de prática, responsável na época pelo Grupo de Convivência, com supervisão direta dos docentes envolvidos, foi estruturado com previsão de carga horária para o acesso aos CAPS/UBS, na intenção de estreitamento do vínculo entre as instituiçóes. Contudo, deparamo-nos concretamente com ligaçóes rápidas, possibilidades de conversa e reunióes reduzidas e sem maior sistematização do contato entre as instituições. As açôes da AAG, ainda, compreenderam a divulgação de sua grade de atividades aos CAPS da região por meio de e-mails e folders ${ }^{3}$.

Cabe lembrar algo importante: é uma das tarefas do CAPS a estruturação organizacional e estratégica da rede de serviços territorial para compor açóes integradas, para auxiliar pessoas com transtorno e/ou sofrimento mental (BRASIL, 2004b, 2011). Mesmo na construção inversa do caminho, o que invariavelmente apresenta-se como também necessária e, sem dúvidas, otimizadora do cuidado, as açôes da AAG não encontraram ressonância junto aos CAPS contatados. Apenas os profissionais de um dos CAPS contatados organizaram-se para realização de uma única reunião junto aos profissionais da AAG.

Outra sorte de ausência, ainda, deve ser trabalhada antes do aprofundamento analítico e propositivo intencionado a este item.

Entrevistadora: "E como é essa experiência pra você? De participar do grupo de convivência?" S2: "Dependendo da atividade élegal, né? Depende do humor, de como às vezes eu estou de saúde, ai tenho ânimo de vir senão, às vezes, o tempo também colabora, a gente já fica meio depressivo, mas, com 
relação ao grupo mesmo, a atividade é... beleza”. Entrevistadora: "E essas vezes que você não pôde participar, você sabe apontar as dificuldades que você [...] encontrou?" S6: "Sinceramente, essa questâo assim, de não poder participar mais vezes, foi culpa minha, pois eu não me programava pra chegar aqui no horário, eu chegava já tinham ido. E eu falava: não, semana que vem eu vou vir no horário dai sempre me atrasava, me atrasava...". S8: "uma dificuldade maior que eu sempre bato na mesma tecla é esse sentimento de inferioridade, de... de medo de sair da toca...". S7: "Huum... Ah, tipo assim, se algum dia, não sei, um dia tiver assim meio de baixo astral, não quiser ir e tal...".

Durante a realização do Grupo de Convivência, algumas pessoas tinham sua frequência interrompida por diferentes situaçóes, as quais eram permeadas por problemas familiares, agravo da doença, humor, etc. Concretamente, a instituição que abrigava o Grupo de Convivência apresentava carências diversas de corpo profissional, a maioria deste era composto por voluntários que se dedicavam à instituição de maneira pontual, coordenando uma ou outra atividade. As ausências e desvinculaçôes, então, não encontravam suporte estrutural da associação para proporcionar maior investimento na exploração dos casos de ausência, nem para realizar uma busca ativa mais densa junto aos usuários. Nesse sentido, o trabalho em rede como diretriz-guia para o trabalho em saúde mental é um conceito que náo surge de maneira despropositada (BRASIL, 1990; LIBERATO, 2009).

A desvinculação do Grupo, seja por conta de um internamento, seja por conta dos eventuais "Baixos astrais" (S7) ou qualquer dificuldade, sem maiores acompanhamentos integrados entre AAG, Unidade Básica de Saúde (UBS) e CAPS, demonstrou pontualmente em nossa experiência a fragilidade da integração da rede de serviços. Açóes diversas entre os profissionais destes serviços devem ser congregadas para garantir acompanhamento próximo ao usuário, seus familiares e suas dificuldades (SILVA; RODRIGUES, 2010). Estruturalmente, por exemplo, não conseguimos, ainda, por falta de recursos humanos, fazer visitas domiciliares aos usuários que param de frequentar o Grupo, para aprofundarmo-nos sobre possíveis impedimentos ou estratégias para ampliar sua participação. Contudo, tal estratégia pode ser pragmatizada pelo CAPS ou pela UBS de sua referência e novas estratégias poderiam, desta forma, ser elaboradas em conjunto entre todos os serviços envolvidos, uma vez que a inclusão social requer trabalho integrado e conciso.

Acreditamos, ainda, enquanto possibilidade de fluxograma, que a expansão das ações do técnico de referência (BRASIL, 2004b) do CAPS ou da UBS pode ser proveitosa, para proporcionar possibilidades organizacionais à tessitura orgânica do trabalho em rede. O profissional do CAPS ou da UBS poderia, para além de se tornar referência de alguns usuários/ família, compor relação mais próxima com algumas instituiçóes, de maneira a estabelecer relação de referência entre estas e o serviço que trabalha e, com isso, acompanhar com maior realce o usuário na construção compartilhada de seu projeto de vida. Ao momento da realizaçáo do Grupo, contudo, diferentes CAPS da região sequer apresentavam a configuração do técnico de referência no exercício de suas atribuiçôes. A Figura 1 apresenta uma possível proposta organizacional para o trabalho em rede em saúde - para dar corpo ao exemplo que propomos, utilizaremos o CAPS como figura central - o que pode ser ampliado para outros equipamentos.

Tal ampliação da proposta do técnico de referência e da reserva a usuários e familiares para equipamentos sociais diversos que compóem o território poderia potencializar diferentes nuances do trabalho em rede e, com isso, maturar sua prática. A especificidade do contato entre a AAG, ao nosso exemplo, com um determinado profissional de um serviço de saúde poderia fortalecer o vínculo entre as instituiçôes em questão, as quais teriam como referência não somente as diretrizes-guias etéreas do trabalho em rede para sua prática (BRASIL, 2004b, 2011), mas sim subjetividades e relaçóes humanas entre seus profissionais, as quais permeariam e dariam suporte pragmático às diferentes parcerias institucionais. Para além, tal aproximação poderia, ainda, alicerçar de maneira mais orgânica e resolutiva diferentes encaminhamentos, comunicados a respeito do atual estado dos usuários, sua frequência e quadro e relaçôes familiares, podendo, também, proporcionar estruturação de ações interinstitucionais.

Em conjugação com o conceito de rede de apoio social delineado inicialmente, as açóes do Grupo de Convivência tornam-se fragilizadas, se o investimento se der com exclusividade sobre a rede de apoio social primária. A relaçáo entre os serviços e o suporte integrado proporcionado ao usuário pode, de maneira incontestável, proteger sua saúde e garantir maior acompanhamento ao usuário em seu processo de vida, tornando, dessa forma, o conceito de rede social de apoio secundária formal e de terceiro setor de importante conjugação com a prática profissional em saúde mental. 


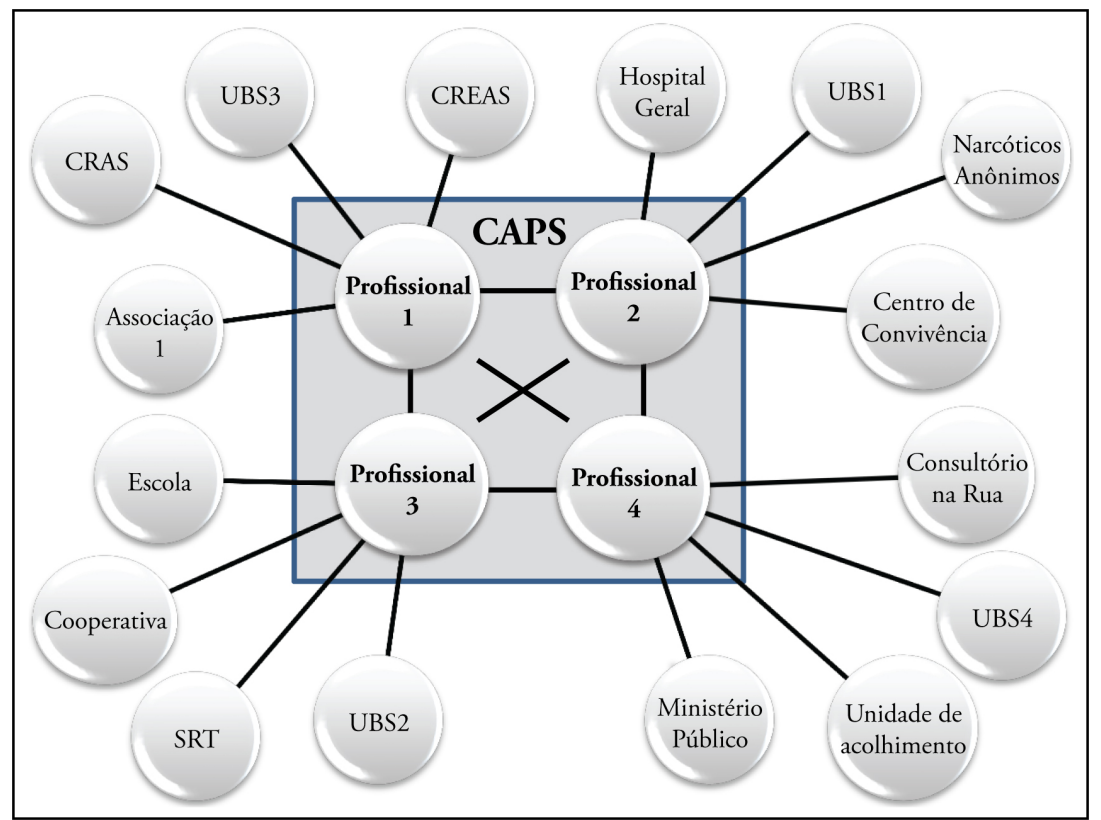

Figura 1. Proposta Organizacional para o trabalho em rede.

De maneira crítica e conjugada com a vertente analítica proposta neste manuscrito, cabe, contudo, apontar uma das atuais mazelas sociais que invariavelmente permearia a proposta e lhe diminuiria a potência: o fluxo intenso de profissionais. Em trabalho anterior (FERRO et al., 2013b), pudemos constatar o grande fluxo de profissionais dos CAPS no município de Curitiba. Como pano de fundo na cidade, naquela época, encontrávamos a maioria dos vínculos empregatícios dos CAPS do município estabelecidos por meio de parcerias com ONGs locais. Baixos salários, falta de plano de carreira e estabilidade, condiçôes de trabalho precárias e falta de investimento em educação continuada proporcionaram pano de fundo propício para compor tal quadro.

Ao que nos tange, gostaríamos de desmistificar uma questão: a concretude cotidiana do trabalho em rede não se constitui de maneira absoluta, tomando ponto de apoio exclusivo em demandas ministeriais e/ou legislativas. O trabalho em rede, enquanto prática, é balizado por microrrelaçóes que vão se estabelecendo paulatinamente entre pessoas. A relação de confiança interinstitucional, a elaboração conjunta de projetos e açóes, e a história estabelecida entre pessoas e instituições são potencializadas quando forjadas também de maneira longitudinal e, para tanto, necessita de relaçóes e vínculos empregatícios que possam proporcionar sua manutenção longitudinal.

Sem a pretensão de explorar em maior minúcia as mazelas para o exercício do trabalho em rede, perpassando pelos aspectos da falta de capacitaçáo profissional, da impregnação do modelo biomédico no campo da saúde, da falta de recursos humanos e de investimento público que deem suporte à sua prática, etc. (TRAD; ROCHA, 2011; LOCH-NECKEL et al., 2009; LUCCHESE et al., 2009; OLIVEIRA et al., 2014; SILVA et al., 2014) resignar-me-ei aqui, como epílogo deste item, a ressaltar a necessidade de organização do trabalho em saúde mental - e não só - para proporcionar de maneira concreta a tecitura de relaçôes interinstitucionais e, com isso, propiciar maior suporte ao acompanhamento e ao cuidado a seus usuários.

\section{Continuidade das ações: entre investimentos públicos e o cuidado}

A partir do ensejo proporcionado pela categoria anterior, afirmando a importância da existência de uma rede concisa e congregada de açóes entre os diferentes equipamentos sociais e seus profissionais, cabe nos aprofundarmos em um ponto: a necessidade de continuidade das açóes.

Entrevistadora: "E agora que não está tendo o grupo de convivência, que está em periodo de férias, como está sua tua rotina de passeio, de lazer, de convivência?" S8: "Tá muito baixa. A única coisa que eu estou fazendo de bom é que ir com a T. na Federação Espirita. Mas deu uma decaida, bastante! Até agora, 
quando começar o grupo de convivência eu vou tá meio perdidona, assim, de novo, não sei...".

Entrevistadora: "Até se adaptar novamente à rotina de começar a sair?"

S8: "É, começar de novo, mas deu uma decaida. Eu estou de novo um pouquinho pra baixo".

Estas declaraçóes, representativas de uma sorte das falas proferidas pelos participantes do Grupo, relacionam-se e inserem-se, em afronta a um possível enquadre individualizante, em um panorama mais amplo - e tal elucidação impóe-se como imprescindível à vertente analítica aqui proposta. Algumas das limitaçôes a serem observadas: o Grupo de Convivência apresentava exclusiva ligação com o estágio realizado pelo curso de Terapia Ocupacional da UFPR, sob supervisão direta dos Docentes do curso. Por sua estrutura vinculada ao estágio de prática da UFPR, o Grupo funcionava somente em período letivo e sem nenhum suporte de investimentos públicos na contratação de profissionais para dar continuidade ao Grupo em momentos de férias estudantis.

Entrevistadora: "E o Sr.participou do grupo de convivência, né? O Sr. pode me contar um pouco como era o grupo, o que vocês fizeram?"

S10: "Elas cuidavam muito bem da gente e deixa saudade, porque elas foram embora, né?"

Entrevistadora: "Foram...".

S10: "Foram amorosas, prestativas, um bom relacionamento que nós tivemos".

As ações do Grupo de Convivência junto aos usuários, por vezes, não apresentam a potencialidade maximizada do acompanhamento em longo prazo dos usuários por um profissional vinculado de maneira integral ao serviço. A Universidade, embora possa auxiliar iniciativas diversas, fortalecendo-as de diferentes maneiras, seja através de verbas e editais próprios, seja através de recursos humanos ou possibilidade de acionar infraestrutura (como ônibus, material de divulgaçáo, etc.), apresenta importantes restrições para proporcionar de maneira autônoma a continuidade das açôes.

Entrevistadora: "Vocêjá tinha vivenciado um grupo de convivência antes, fora daqui? Fora da associaçẫo?" S11: "Só aqui".

Alguns sujeitos afirmaram que nunca vivenciaram um Grupo de Convivência em outros serviços. Embora esteja comprometido com o dispositivo, acredito, com base nos mais diferentes relatos, na grande contribuição do Grupo de Convivência para práticas em saúde mental, seja na prevenção, na promoçáo ou na recuperação da saúde (FERRO et al., 2012).

É importante compreender a possibilidade de realização do grupo, ainda, por meio dos mais diferentes equipamentos: UBS, CAPS, Associaçóes, Espaços de Cultura, Igrejas, etc. Contudo, a exploração de uma possível pergunta se faz importante: É necessário que o grupo seja coordenado por um profissional da saúde?

Diferentes atores sociais vêm compondo açôes de enfrentamento ao isolamento social, sejam estes voluntários de associaçóes, igrejas, clubes comunitários, etc. Contudo, acreditamos, ao menos por nossa experiência na saúde mental, ser imprescindível, ao mínimo, proximidade continuada de profissionais dos equipamentos de saúde e/ou assistência social dos usuários encaminhados, proporcionando tanto estrutura para seu acompanhamento quanto ao coordenador do grupo, seja por meio do acompanhamento conjunto de usuários/grupo, seja na realização de açôes de educação em saúde. Para além, é mister desenvolver açôes por meio das quais os profissionais possam proporcionar aos coordenadores do grupo uma relação de parceria e referência com o serviço de saúde, para acionamento sob qualquer eventualidade que venha abater os usuários participantes.

Concomitantemente, toma importância a elaboração de estratégias para fortalecer as açōes dos agentes promotores dos grupos em questáo, de maneira a garantir a continuidade destes serviços. Seria interessante que a criação e a continuidade de um grupo de convivência não sofressem as intempéries próprias ao trabalho voluntariado ou às férias de um estágio curricular. Embora quebras de continuidade permeiem o SUS em suas mais variadas formas (desvinculação de profissionais, falta de recursos, mudanças políticas, quebra de contratos com prestadores de serviço, etc.), investimentos públicos, seja através de fomento às associaçóes para a contratação profissional, seja a partir da implantação de Centros de Convivência, equipamento já legislativamente configurado dentro da Rede de Atenção Psicossocial, podem ser passos estruturais que promovam a continuidade das açôes.

Logo, a continuidade, tema deste subitem, teria sua importância em tripla vertente: na garantia longitudinal do acompanhamento do usuário em espaços de vida fora dos equipamentos de saúde, por seus profissionais de referência; na possibilidade estratégica de suporte de profissionais vinculados aos equipamentos de saúde/assistência social à edificação e ao fortalecimento do grupo, mesmo que realizados pelas diferentes entidades sociais; na atitude propositiva do poder público quanto ao fomento e à estruturação de espaços de convivência. A análise do tema continuidade, desta maneira, afirma sobremaneira a importância do investimento em ações para o fortalecimento das redes sociais de apoio 
secundárias e terciárias ${ }^{4}$ para, assim, proporcionar maior concisão às práticas em saúde mental.

\section{Grupo de convivência: sustentabilidade para a participação}

Diversos usuários relataram dificuldades em manter sua participação em todos os encontros do Grupo de Convivência.

Entrevistadora: "Você vivenciou alguma barreira para sua participação no grupo de convivência?” S2: "Às vezes relacionada à situação financeira. Porque às vezes não dava, não tinha trabalhado naquela semana, dai queria ir pra Ilha do Mel... Eu acho que seria ideal ter a atividade gratuita e com apoio e colaboração da Universidade principalmente pra passeios! Eu acho que essa atividade do grupo de convivência é muito importante".

Entrevistadora: "Mesmo participando em todos os encontros, o que você achou dificil às vezes, ou limitante...".

S4: "Um pouco o financeiro".

Para tentar possibilitar à maioria dos usuários a participação no Grupo, diversos passeios são realizados em locais gratuitos, como parques, museus, espaços parceiros, entre outros; contudo, mesmo com passeios com gastos reduzidos ao máximo, como um dos sujeitos lembra, "é... tem os ônibus, né, que tem que pagar...” (S4).

Alguns sujeitos revelam, em seus contrapontos, a importância de uma rede social de apoio para auxílio à participação no Grupo.

Entrevistadora: "E nunca teve nenhuma questão financeira?"

S3: "Não porque meu pai emprestava e não era tanto. [Os gastos] Foram pequenos em relação às atividades".

Entrevistadora: "Então você acha que isso não foi uma barreira, um empecilho pra sua participação?" S3: "Não! Barreira não!"

Entrevistadora: "Como é seu final de semana?" S11: "Só fico em casa".

Entrevistadora: "Por que você só fica em casa?" S11: "Não tenho dinheiro pra ir... sair...".

Entrevistadora: "Você acha que não ter dinheiro é uma dificuldade?"

S11: "Exato!"

Entrevistadora: "Você acha que (usuário interrompe)".

S11: "Desempregado... tá pior ainda. E a mãe... éaposentada".
Entrevistadora: "Então você acha que não ter dinheiro te limita a sair?"

S11: "Exato. Quem controla o dinheiro é minha mãe, o dinheiro dela. O dinheiro meu não tenho nenhum, nem INSS eu tenho. [...] É, estou desempregado e, mesmo que consiga emprego, é dificil pra pagar".

Entrevistadora: "Você tem alguma sugestão pra dar pra nós [...] sobre essa questão do dinheiro?"

S11: "Separar o dinheiro da geração de renda pro passeio".

Entrevistadora: "Quem participa da geração de renda poupar".

S11: "Poupar, vai poupando né".

Um dos grupos promovidos, ainda pela parceria entre Associação Arnaldo Gilberti e o Departamento de Terapia Ocupacional da UFPR, é o grupo de geração de renda. Alguns relatos, como é o caso acima, apresentaram a possibilidade de vincular o ganho desse grupo à realização dos passeios.

Um dos pontos, logo, que se mostrou imprescindível para realização e continuidade da atenção e do processo terapêutico em saúde mental é o investimento público em quesitos que transbordam o foco exclusivo da saúde na doença. Vale relembrar insistentemente o artigo terceiro da Lei 8.080 que, desde 1990, afirma:

A saúde tem como fatores determinantes e condicionantes, entre outros, a alimentação, a moradia, o saneamento básico, o meio ambiente, o trabalho, a renda, a educaçáo, o transporte, o lazer e o acesso aos bens e serviços essenciais; os níveis de saúde da população expressam a organização social e econômica do País. Parágrafo único. Dizem respeito também à saúde as ações que, por força do disposto no artigo anterior, se destinam a garantir às pessoas e à coletividade condiçóes de bem-estar físico, mental e social (BRASIL, 1990, s/p).

É de fácil visualização, nas falas acima, a relação intrínseca entre a garantia de direitos básicos do cidadão e a resolubilidade das ações em saúde. $\mathrm{Na}$ época da realização da pesquisa, era premissa, no município de Curitiba, para garantir transporte gratuito ao cidadão que sofre de transtorno mental, que este indivíduo frequentasse, no mínimo, três vezes por semana, espaços de saúde.

Bem, ao menos em saúde mental, diversas problemáticas no tocante a este ponto não podem ser omitidas. Se os serviços de saúde devem prezar a inclusão social (BRASIL, 2004a), propondo vinculação deste sujeito a espaços diversos de convivência, na direção da ampliação da qualidade de vida em interface com açốes de prevenção, promoção e 
mesmo recuperação da saúde, há dissonância clara com tal benefício.

A partir do momento em que os profissionais do CAPS e da UBS conseguem vincular estes indivíduos a outros espaços, como o grupo de convivência, e o investimento público para o cuidado em saúde cessa, alguns dos indivíduos - em especial, indivíduos em maior vulnerabilidade -, inevitavelmente, deixarão de participar de açôes para manutenção de sua saúde - o ciclo da doença instaura-se e o processo terapêutico é quebrado.

Não afirmamos aqui a solução pronta da problemática na permanência do benefício, esta questáo imerge em território de maior complexidade. Para que as açóes em Saúde Mental, pautadas na diretriz da inclusão social, possam tomar efetividade concreta, são necessárias medidas para a garantia dos direitos sociais básicos: moradia, trabalho, saúde, alimentação, educação, lazer e renda.

Embora alguns dos usuários explicitem a possível interface do Grupo de Convivência com o Grupo de Geração de Renda, referindo a possibilidade de poupar para participar dos passeios, esta outra iniciativa - material para exploraçáo pormenorizada em outra oportunidade - ainda apresenta limitaçóes concretas na geraçáo de renda e fragilidade de apoio governamental para autossustentabilidade (SINGER, 2001; FERRO; CARDOSO; LOUREIRO, 2015).

\section{Conclusão}

Durante o corpo textual, pode-se perceber que a prática do Grupo de Convivência é permeada por diferentes fatores: individuais, familiares, financeiros, integração entre diferentes equipamentos sociais e seus profissionais, e legislativos. Longe da acrítica assunção do Grupo de Convivência enquanto dispositivo hermeticamente ensimesmado em sua excelência na ampliação das redes sociais de apoio à populaçáo atendida pela Saúde Mental, interessou-me, nesta oportunidade, conjugá-lo em sua interface a uma rede de atenção.

As premissas do trabalho em rede e intersetorial, previstas pelo SUS e pela atual RAPS, para além de aéreas concepções, debruçam-se sobre um cotidiano concreto de práticas. A análise que procurei realizar, utilizando-me, neste percurso dissertativo, do conceito de redes sociais de apoio, procurou aterrissar tais premissas em plano concreto e cotidiano, advindo da prática de um grupo de convivência. Procurei, ainda, trabalhar analiticamente proposiçóes organizacionais para os serviços de saúde que podem, também, servir de subsídios para os demais serviços da rede na composição de açôes estratégicas em saúde mental.
Diversas limitaçóes evidenciadas na prática cotidiana da execução do Grupo, de Convivência, sustentadas por diferentes relatos, dão ênfase à afirmativa de que a busca pela efetividade do dispositivo "Grupo de Convivência” transpassa sua execução microestrutural. A falta de apoio dos diferentes equipamentos sociais, de seus profissionais e da legislação - ou, pelo menos, a falta de garantia de sua aplicação pragmática; a falta de ações estratégicas, elaboradas por equipes de diferentes serviços, para enfrentamento de problemáticas diversas vivenciadas pela população alvo; a fragilidade da corresponsabilização dos casos entre serviços e profissionais, e a falta de continuidade das açôes públicas compóem quadro avesso e substancialmente enfraquecedor das açôes em saúde. E o grupo de convivência não se abstém das influências negativas desse quadro mais amplo.

É importante afirmar aqui, sim, diferentes potencialidades do dispositivo; contudo, é necessário sublinhar também sua potência ainda adormecida e estanque, no aguardo da pragmatizaçáo dos conceitos de Trabalho em Rede e Intersetorialidade, previstos legislativamente já na década de 1980.

\section{Agradecimentos}

Às terapeutas ocupacionais Caroline Cristina Fracaro e Giovana Fedato, pela parceria na coleta dos dados, e à Prof.a Mônica de Macedo Cardoso, pela idealização do Grupo de Convivência.

\section{Referências}

AMARANTE, P. Arquivos de saúde mental e atenção psicossocial. Rio de Janeiro: NAU, 2003.

ANTUNES, E. H.; BARBOSA, L. H. S.; PEREIRA, L. M. F. Psiquiatria, loucura e arte. São Paulo: EDUSP, 2002.

BALLARIN, M.L.S.G. Algumas reflexóes sobre grupos de atividades em terapia ocupacional. In: PÁDUA, E. M. M.; MAGALHÃES, R. V. (Org.). Terapia ocupacional: teoria e prática. Campinas: Papirus, 2003. p. 62-76.

BAZHUNI, N. F. N. Circunscrevendo o campo diverso, diferente e divergente do acompanhamento terapêutico. São Paulo: Biblioteca 24horas, 2011.

BRASIL. Lei n ${ }^{\circ}$ 8.080, de 19 de setembro de 1990. Dispóe sobre as condiçōes para a promoção, proteção e recuperação da saúde, a organização e o funcionamento dos serviços correspondentes, e dá outras providências. Diário Oficial [da] República Federativa do Brasil, Poder Executivo, Brasília, DF, 20 set. 1990. Disponível em: <http://www.planalto.gov.br/ccivil_03/leis/18080.htm>. Acesso em: 15 dez. 2014.

BRASIL. Lei n ${ }^{\circ} 10.216$, de 06 de abril de 2001. Dispóe sobre a proteção e os direitos das pessoas portadoras de transtornos mentais e redireciona o modelo assistencial em saúde mental. Diário Oficial [da] República Federati- 
va do Brasil, Poder Executivo, Brasília, DF, 6 abr. 2001. Disponível em: <http:/www.planalto.gov.br/ccivil_03/ leis/leis_2001/110216.htm>. Acesso em: 23 jul. 2015.

BRASIL. Ministério da Saúde. Secretaria-Executiva. Secretaria de Atençáo à Saúde. Legislação em saúde mental: 1990-2004. Brasília, 2004a.

BRASIL. Ministério da Saúde. Secretaria de Atenção à Saúde. Saúde mental no SUS: os centros de atençáo psicossocial. Brasília, 2004b. Disponível em: <http://www. ccs.saude.gov.br/saude_mental/pdf/SM_Sus.pdf $>$. Acesso em: 15 dez. 2014 .

BRASIL. Ministério da Saúde. Saúde mental e economia solidária: inclusão social pelo trabalho. Brasília, 2005.

BRASIL. Ministério da Saúde. Portaria n³.088, de 23 de dezembro de 2011. Institui a Rede de Atenção Psicossocial para pessoas com sofrimento ou transtorno mental e com necessidades decorrentes do uso de crack, álcool e outras drogas, no âmbito do Sistema Único de Saúde. Diário Oficial [da] República Federativa do Brasil, Poder Executivo, Brasília, DF, 26 dez. 2011. Disponível em: <http://bvsms.saude.gov.br/bvs/saudelegis/gm/2011/ prt3088_23_12_2011_rep.html>. Acesso em: 15 dez. 2014.

CHIAVERINI, D. H. Guia prático de matriciamento em saúde mental. Brasília: Ministério da Saúde, 2011.

DESSEN, M. A.; BRAZ, M. P. Rede social de apoio durante transiçóes familiares decorrentes do nascimento de filhos. Psicologia: Teoria e Pesquisa, Brasília, v. 16, n. 3, p. 221-231, 2000. http://dx.doi.org/10.1590/S010237722000000300005 .

FASSHEBER, V. B.; VIDAL, C. E. L. Da tutela à autonomia: narrativas e construçóes do cotidiano em uma residência terapêutica. Psicologia: ciência e profissão, Brasília, v. 27, n. 2, p. 194-207, 2007.

FERRO, L. F. Trabalho territorial em hospitais psiquiátricos: construindo no presente um futuro sem manicômios. Psicologia: Ciência e Profissão, Brasília, v. 29, n. 4, p. 752-67, 2009. http://dx.doi.org/10.1590/S141498932009000400008 .

FERRO, L. F. et al. Grupo de convivência em saúde mental: perspectivas de usuários e a experiência do curso de Terapia Ocupacional da Universidade Federal do Paraná. Revista de Terapia Ocupacional da Universidade de São Paulo, São Paulo, v. 23, n. 2, p. 146-152, 2012. http://dx.doi.org/10.11606/issn.2238-6149.

FERRO, L. F. et al. Controle social e açôes em saúde: possibilidades estratégicas de trabalho. In: CONGRESSO INTERNACIONAL DE SAÚDE MENTAL, 2., 2013, Irati. Anais... Paraná: Universidade Estadual do Centro-Oeste, 2013a.

FERRO, L. F. et al. A terceirização dos serviços de saúde mental: o CNES como instrumento de pesquisa. In: ENCONTRO NACIONAL DE REDES DE ATENÇÃO PSICOSSOCIAL DO SUS, 1., 2013, Pinhais. Anais... Pinhais: Ministério da Saúde, 2013b.

FERRO, L. F.; CARDOSO, M. M.; LOUREIRO, M. B. Economia Solidária, Saúde Mental e a prática do terapeuta ocupacional: relatos de participantes de um grupo de geração de trabalho e renda. Cadernos de Terapia
Ocupacional da UFSCar, São Carlos, v. 23, n. 1, p. 101116, 2015. http://dx.doi.org/10.4322\%2F0104-4931. ctoAO500.

FILIZOLA, C. L. A. et al. Saúde Mental e Economia Solidária: a família na inclusão pelo trabalho. Revista $d a$ Escola de Enfermagem da USP, São Paulo, v. 45, n. 2, p. 418-425, 2011. http://dx.doi.org/10.1590/S008062342011000200017 .

FONSECA, M. A. A prática do terapeuta ocupacional em saúde mental a partir de uma perspectiva não excludente e de respeito às diferenças. In: DRUMOND, A. F; REZENDE, M. B. (Org.). Intervençóes da terapia ocupacional. Minas Gerais: UFMG, 2008. p. 71-94.

HAYAKAWA, L. Y. et al. Rede social de apoio à família de crianças internadas em uma unidade de terapia intensiva pediátrica. Revista Brasileira de Enfermagem, Brasília, v. 63, n. 3, p. 440-445, 2010. http://dx.doi.org/10.1590/ S0034-71672010000300015. PMid:20658080.

JUSSANI, N. C.; SERAFIM, D.; MARCON, S. S. Rede social durante a expansão da familia. Revista Brasileira de Enfermagem, Brasília, v. 60, n. 2, p. 184-189, 2007. http://dx.doi.org/10.1590/S003471672007000200011 . PMid:17585525.

KINKER, F. S. Enfrentamentos e construção de projetos de trabalho para a superaçáo da laborterapia. $C a-$ dernos de Terapia Ocupacional da UFSCar, São Carlos, v. 22, n. 1, p. 49-61, 2014. http://dx.doi.org/10.4322/ cto. 2014.006

LIBERATO, M. D. M. Desinstitucionalizar é ultrapassar fronteiras sanitárias: o desafio da intersetorialidade e do trabalho em rede. Caderno Brasileiro de Saúde Mental, Florianópolis, v. 1, n. 1, p. 1-10, 2009.

LOCH-NECKEL, G. et al. Desafios para a ação interdisciplinar na atenção básica: implicações relativas à composiçáo das equipes de saúde da família. Ciência \& Saude Coletiva, Rio de Janeiro, v. 14, n. 1, p. 1463-1472, 2009. http://dx.doi.org/10.1590/S141381232009000800019 . PMid:19750355.

LUCCHESE, R. et al. Saúde mental no Programa Saúde da Família: caminhos e impasses de uma trajetória necessária. Cadernos de Saúde Pública, Rio de Janeiro, v. 25, n. 9, p. 2033-2042, 2009. http://dx.doi.org/10.1590/ S0102-311X2009000900017. PMid:19750390.

MÂNGIA, E. F; MURAMOTO, M. Redes sociais e construção de projetos terapêuticos: um estudo em serviço substitutivo em saúde mental. Revista de Terapia Ocupacional da Universidade de São Paulo, São Paulo, v. 18, n. 2, p. 54-62, 2007.

MARCONI, M. A.; LAKATOS, E. M. Fundamentos de metodologia cientifica. Sáo Paulo: Atlas, 2007.

MARQUES, E. S. et al. A influência da rede social da nutriz no aleitamento materno: o papel estratégico dos familiares e dos profissionais de saúde. Ciência \& Saúde Coletiva, Rio de Janeiro, v. 15, n. 1, p. 1391-1400, 2010. http://dx.doi.org/10.1590/S141381232010000700049. PMid:20640299.

MINAYO, M. C. S. Pesquisa social: teoria, método e criatividade. Rio de Janeiro: Vozes, 2003 
MINAYO, M. C. S. O desafio do conhecimento: pesquisa qualitativa em saúde. Sáo Paulo: Hucitec, 2004.

MOURA, A. C. M. D.et al. A relação entre sujeitos com transtorno mental e equipamentos sociais.Cadernos de Terapia Ocupacional da UFSCar, São Carlos, v. 22, n. 2, p. 263-270, 2014. http://dx.doi.org/10.4322/ cto.2014.048.

OLIVEIRA, F. R. L. et al. Interdisciplinaridade e intersetorialidade na Estratégia Saúde da Família e no Núcleo de Apoio à Saúde da família: potencialidades e desafios. O Mundo da Saúde, São Paulo, v. 38, n.2, p.129-138, 2014. http://dx.doi.org/10.15343/01047809.20143802129138 .

OLIVEIRA, G. N. O Projeto terapêutico como contribuição para a mudança das práticas de saúde. $2007.176 \mathrm{f}$. Dissertação (Mestrado em Saúde Coletiva)-Universidade Estadual de Campinas, Campinas, 2007.

OLIVER, F. C. et al. Participação e exercício de direitos de pessoas com deficiência: análise de um grupo de convivência em uma experiência comunitária. Interface: Comunicação, Saúde, Educação, Botucatu, v. 8, n. 15, p. 275-288, 2004. http://dx.doi.org/10.1590/S141432832004000200007.

SILVA, K. L.; RODRIGUES, A. T. Ações intersetoriais para promoção da saúde na Estratégia Saúde da Família: experiências, desafios e possibilidades. Revista Brasileira de Enfermagem, Brasília, v. 63, n. 5, p. 762-769, 2010. http://dx.doi.org/10.1590/S003471672010000500011. PMid:21103769.

SILVA, L. G.; CORTEGOSO, A. L.; LUSSI, I. A. O. $\mathrm{Da}$ orientação profissional à inserção laboral de usuários de serviços de saúde mental em empreendimentos econômicos solidários. Cadernos de Terapia Ocupacional da UFSCar, São Carlos, v. 22, n. 2, p. 271-283, 2014. http://dx.doi.org/10.4322/cto.2014.049.
SILVA, M. R. M. O. et al. Desenvolvendo e articulando a rede intersetorial para cuidado integral de usuários de drogas em contextos de vulnerabilidade.Cadernos de Terapia Ocupacional da UFSCar, São Carlos, v. 22, n SE, p. 145-152, 2014. http://dx.doi.org/10.4322/ cto.2014.039.

SINGER, P. Autogestão e socialismo: oito hipóteses sobre a implantação do socialismo via autogestão. In: OLIVEIRA, P. S. (Org.). O lúdico na cultura solidária. São Paulo: Hucitec, 2001. p. 229-239.

SOUZA, M. H. N.; SOUZA, I. E.; TOCANTINS, F. R. A utilização do referencial metodológico de rede social na assistência de enfermagem a mulheres que amamentam. Revista Latino-Americana de Enfermagem, Ribeirão Preto, v. 17, n. 3, p. 354-360, 2009. PMid:19669046.

SOUZA, V. C. A.; PEREIRA, A. R.; GONTIJO, D. T. A experiência no serviço de consultório na rua na perspectiva dos profissionais: contribuiçóes para a atenção ao usuário de álcool e outras drogas. Cadernos de Terapia Ocupacional da UFSCar, São Carlos, v. 22, n SE, p. 37-47, 2014. http://dx.doi.org/10.4322/ cto.2014.028.

TRAD, L. A. B.; ROCHA, A. A. R. M. Condiçóes e processo de trabalho no cotidiano do Programa Saúde da Família: coerência com princípios da humanização em saúde. Ciência \& Saúde Coletiva, Rio de Janeiro, v. 16, n. 3, p. 1969-1980, 2011. http://dx.doi.org/10.1590/ S1413-81232011000300031. PMid:21519685.

VIEIRA FILHO, N. G.; NÓREGA, S. M. A atenção psicossocial em saúde mental: contribuição teórica para o trabalho terapêutico em rede social. Estudos de Psicologia, Natal, v. 9, n. 2, p. 373-379, 2004. http://dx.doi. org/10.1590/S1413-294X2004000200020.

ZACCARIN, S.; RIVELLINI, G. Reti di relazioni e comportamento individuale: lápproccio della social network analysis. Trieste: Università di Trieste, 2000.

\section{Notas}

${ }^{1} \mathrm{O}$ trabalho é resultante de projeto de pesquisa e intervenção. O texto é fruto da pesquisa científica "Grupo de Convivência em Saúde Mental: Potencialidades e Limitações sob a ótica de usuários” aprovada pelo Comitê de Ética em Pesquisa em Seres Humanos (CEP/UFPR) sob o no 1074.199.10.12.

${ }^{2}$ Diferentes denominaçôes são utilizadas ao conceito: rede social, rede de apoio, apoio social, rede social de apoio. O presente trabalho opta por utilizar a expressão rede social de apoio para clarear a diferenciação do atual conceito de 'redes sociais', atualmente bastante vinculado às possibilidades de relacionamento virtual.

${ }^{3}$ Cabe lembrar que a condução do Grupo de Convivência foi transferida para um estágio de observação de quatro horas, o que inviabilizou a realização destas diferentes açóes em rede e restringiu a açáo dos Docentes exclusivamente à coordenação restrita ao grupo.

${ }^{4}$ Em estudo anterior, pudemos trabalhar sobre reflexôes e configuraçôes possíveis internas ao grupo de convivência para proporcionar suporte a momentos de ausência de coordenação, dando maior ênfase às açóes para o estabelecimento mais conciso da rede social de apoio primária (FERRO et al., 2012). 